\title{
Vitamin D deficiency and its impact on asthma severity in asthmatic children
}

\author{
Nasrin Esfandiar ${ }^{1}$, Fariba Alaei ${ }^{2}$, Shahrzad Fallah ${ }^{3}$, Delara Babaie ${ }^{4^{*}}$ and Niloofar Sedghi ${ }^{1}$
}

\begin{abstract}
Background: Despite obtaining evidences on association between vitamin D and development of lung in fetus, little is known about vitamin D level and its impact on severity of asthma in children. The present study aimed to assess the relationship between the asthma severity and vitamin D deficiency in asthmatic children.

Methods: This case-control study was conducted on 106 individuals including asthmatic $(n=53)$ and healthy children $(n=53)$ who referred to Mofid hospital in Tehran in 2013. The level of serum vitamin D in both groups was measured by radioimmunoassay method at the reference lab and was categorized as sufficient $(>30 \mathrm{ng} / \mathrm{ml}$ ), insufficient ( 20 to $30 \mathrm{ng} / \mathrm{ml})$, or deficient $(<20 \mathrm{ng} / \mathrm{ml})$. The control status of asthma in patients group was classified as controlled, partially controlled, and uncontrolled.

Results: In the groups with and without asthma, the prevalence of vitamin D deficiency was 73.6 and 49.1\%, and the prevalence of vitamin D insufficiency was 18.9 and 18.9\%, while normal vitamin D level was revealed in 7.5 and $32.1 \%$, respectively with a significant difference $(p=0.005)$. Using the multivariate logistic regression analysis, the presence of asthma was associated with reduced level of vitamin $D(O R=1.068,95 \% \mathrm{Cl}: 1.027-1.110, P=0.001)$. In this context, the risk for asthma in the children with vitamin D deficiency was 6.3 times of those with normal vitamin D level. Although the presence of asthma was strongly associated with reduced level of vitamin D in serum, neither severity of asthma nor control status of asthma were associated with vitamin D deficiency.
\end{abstract}

Conclusion: The presence of vitamin D deficiency effectively predict increased risk for childhood asthma; however the severity or control status of this event may not be predicted by confirming vitamin D deficiency.

Keywords: Asthma, Vitamin D, Children, Risk

\section{Background}

The upward trend of morbidity and high socioeconomic burden of asthma in children has prompted scientists to seek both genetic and environmental factors contribute to this phenomenon. Recently, the relationship between vitamin $\mathrm{D}$ deficiency and pediatrics asthma has been supported by some clinical studies [1]. Recent studies introduced a genetic factor, vitamin D receptor gene polymorphisms, that is responsible for vitamin D deficiency in children. In this regard, the predictive role of some polymorphisms such as FokI, ApaI, and TaqI has been suggested, but not completely understood [2]. Also, in a developing long time series transcriptome data (DLCGS) in order to infer the role of in utero changes of vitamin

\footnotetext{
* Correspondence: delara77@yahoo.com

${ }^{4}$ Allergy and Clinical Immunology Department, Mofid Children's Hospital,

Shahid Beheshti University of Medical Sciences, Tehran, Iran

Full list of author information is available at the end of the article
}

$\mathrm{D}$ responsive genes in both the developing lung and asthma, some evidences have been obtained the set of vitamin D related genes to be associated with lung development [3], but these gene associations have not been clearly determined in other population-based studies. On the other hand level of $\mathrm{pH}$ in exhaled breath condensate decrease in asthma exacerbations [4], and vit-D deficiency aggravates oxidative stress and DNA damage [5]. Clinically, the association between vitamin $\mathrm{D}$ and fetal lung development has been also revealed in both animal and fetal models. In animal studies, it has been found that rachitic rat pups born to vitamin $\mathrm{D}$ deficient mothers had reduced lung compliance and also delayed alveolar development $[4,6,7]$. It has been also shown vitamin D3 as a main growth factor necessary for proliferation of alveolar type-II cells and the vitamin D receptors has been characterized in alveolar epithelial cells [8]. Additionally, it has been revealed that exposure to 
vitamin $\mathrm{D}$ in fetus leads to increase in surfactant synthesis and secretion [9-11]. There is an important point that vitamin $\mathrm{D}$ deficiency is a common finding among children and young adolescent whole of the world especially in our country. In a study among Iranian young students, more than half of them suffered vitamin D deficiency [12]; however, we could not find a comprehensive data on the prevalence of vitamin D deficiency among Iranian infants. Despite obtaining evidences on association between vitamin D and development of lung in fetus, little is known about vitamin D levels and their impact on severity of asthma in children. Hence, we hypothesized that the children with severe asthma had lower level of vitamin D. The present study aimed to assess the relationship between the severity of asthma and severity of vitamin D deficiency in asthmatic children.

\section{Methods}

This case-control study was conducted on 53 asthmatic patients and 53 healthy controls in Mofid hospital, Tehran during 2013. The selection of samples was based on simple census sampling method. The patients aged above 2 years who were diagnosed with asthma and hyperreactive airway disease, were included in the study. Asthma was diagnosed according to the EPR3 and GINA criteria [1, 13]. All included patients gave informed written consent and the study was approved by the ethics committee at Shahid Beheshti University of Medical Sciences (registration number: IR.SBMU. MSP.REC.1392.405). Human rights were respected in accordance with the Helsinki Declaration. The exclusion criteria were having disease or conditions which might affect serum level of vitamin D and or its metabolism, including chronic renal failure, metabolic disorder, malabsorption, cholestasis, refractory Rickets.

The control subjects were randomly selected from children without asthmatic children or other underlying disorders the baseline characteristics were collected from clinical checklist completed by interviewing parents and patients including gender, age, duration of asthma, and hospitalization rate. The level of serum vitamin $\mathrm{D}$ in both groups was measured by radioimmunoassay (RIA) method at the reference lab and was categorized as sufficient (> $30 \mathrm{ng} / \mathrm{ml}$ ), insufficient (20 to $30 \mathrm{ng} / \mathrm{ml}$ ), or deficient $(<20 \mathrm{ng} / \mathrm{ml})$. The severity of asthma was also stratified according to the asthma guideline into four grades of intermittent or mild, moderate, severe persistent [14]. Also, the control status of asthma in patients group was classified as controlled, partially controlled, and uncontrolled based on GINA (Global Initiative for Asthma) criteria including daytime symptoms, limitation of activities, nocturnal symptoms, need for reliever or rescue inhaler, and lung function [13]. Moreover, the risk for appearance of symptoms was assessed based on the frequency of worsening symptoms need to use systemic corticosteroids according to the guidelines $[1,13]$.

For statistical analysis, Results were presented as mean \pm standard deviation (SD) for quantitative variables and were summarized by absolute frequencies and percentages for categorical variables. Categorical variables were compared using chi-square test or Fisher's exact test when more than $20 \%$ of cells with expected count of less than 5 were observed. Quantitative variables were also compared with $t$ test, ANOVA (Analysis of Variance) tests or Mann- Whitney $U$ test. The association between quantitative variables was tested using the Pearson's or Spearman's correlation test. We used the multivariable regression modeling to assess the relation between vitamin D deficiency and severity of asthma with the presence of confounders. For the statistical analysis, the statistical software SPSS version 16.0 for windows (SPSS Inc., Chicago, IL) was used. $P$ values of 0.05 or less were considered statistically significant.

\section{Results}

The two groups were similar in male gender distribution (56.6 versus $59.0 \%, p=0.559)$ and mean age $(5.63 \pm$ 3.24 years versus $5.56 \pm 3.90$ years, $p=0.920$, which $43.4 \%$ in the case group were women and $49.1 \%$ in the control group as well) (Table 1). In asthmatic group, the mean duration of disease was $13.1 \pm 24.6$ months. Regarding rate of admission, $13.2 \%$ of patients were hospitalized once, $9.4 \%$ of patients were hospitalized twice, and $1.9 \%$ of them were also hospitalized three times. In the patients group and regarding the severity of asthma, $11.3 \%$ were classified as mild asthma, $45.3 \%$ as moderate asthma, and $43.4 \%$ as severe asthma. Also regarding control status of asthma, the disease was controlled in $18.9 \%$, partially controlled in $34.0 \%$, and uncontrolled in $47.2 \%$. According to the the level of disease attack risk, 5 of 31 children aged less than 5 years $(16.1 \%)$ classified as high-risk, while 7 of 22 children older than 5 years $(31.8 \%)$ classified as high risk. Assessing the serum level of vitamin D showed that the asthmatic children had significantly lower level of vitamin D compared to normal cases (14.53 \pm 8.10 ng.ml versus $22.45 \pm 13.46 \mathrm{ng} / \mathrm{ml}, \quad p<0.001)$. Also, in the groups with and without asthma, the prevalence of vitamin D deficiency was 73.6 and

Table 1 Patients characteristics in two groups

\begin{tabular}{llll}
\hline & Case & Control & $P$-value \\
\hline Age & $5.6 \pm 3.2$ & $5.5 \pm 3.9$ & 0.902 \\
Female (\%) & $23(43.4 \%)$ & $26(49.1 \%)$ & 0.349 \\
Male & $27(56.6 \%)$ & $30(59.0 \%)$ & 0.559 \\
Vitamin D & $14.5 \pm 8.1$ & $22.4 \pm 13.4$ & 0.0001 \\
\hline
\end{tabular}


49.1\%, and the prevalence of vitamin D insufficiency was 18.9 and $18.9 \%$, while normal vitamin D level was revealed in 7.5 and $32.1 \%$, respectively with a significant difference $(p=0.005)$. As summarized in Figs. 1 and 2, despite the presence of asthma was strongly associated with reduced level of vitamin D in serum, but neither severity of asthma nor lack of controlling disease was associated with vitamin $\mathrm{D}$ deficiency. In this regard, mean serum level of vitamin $\mathrm{D}$ in the patients with mild asthma was $12.85 \pm 7.06 \mathrm{ng} / \mathrm{ml}$, in the group with moderate asthma was $16.98 \pm 8.63 \mathrm{ng} / \mathrm{ml}$, in the patients with severe asthma was $12.42 \pm 7.52 \mathrm{ng} / \mathrm{ml}$, and in those with persistent asthma was $12.01 \pm 5.00 \mathrm{ng} / \mathrm{ml} \quad(p=0.260)$. Furthermore, the mean serum level of vitamin D in children with controlled asthma was $15.11 \pm 8.22 \mathrm{ng} / \mathrm{ml}$, in the group with partially controlled asthma was $15.56 \pm$ $7.88 \mathrm{ng} / \mathrm{ml}$, and in those with uncontrolled asthma was $13.55 \pm 8.42 \mathrm{ng} / \mathrm{ml}$ with no difference $(p=0.711)$. Among children younger than 5 years, no difference was found in low-risk and high-risk subgroups for disease attacks in mean level of vitamin D $(14.40 \pm 10.54 \mathrm{ng} / \mathrm{ml}$ versus $14.53 \pm 7.72 \mathrm{ng} / \mathrm{ml}, p=0.976$ ), while in older group, the level of serum vitamin $D$ was significantly lower in the high-risk group than in low-risk group $(9.21 \pm 3.08 \mathrm{ng} /$ $\mathrm{ml}$ versus $17.05 \pm 8.99 \mathrm{ng} / \mathrm{ml}, p=0.038$ ). There was no difference in mean level of vitamin $\mathrm{D}$ in male and female asthmatic patients $(15.54 \pm 8.79 \mathrm{ng} / \mathrm{ml}$ versus $13.20 \pm 7.07 \mathrm{ng} / \mathrm{ml}, p=0.303)$, whereas an adverse correlation was found between patients' age and level of vitamin $\mathrm{D}(r=-0.300, p=0.029)$ (Fig. 3). No association was revealed between duration of disease and level of vitamin D $(r=-0.155, p=0.267)$. Also, level of vitamin $\mathrm{D}$ was not associated with the frequency of hospitalization $(r=-0.125, p=0.274)$. As shown in
Table 2 and using the multivariate logistic regression analysis, the presence of asthma was associated with reduced level of vitamin $\mathrm{D}(\mathrm{OR}=1.068,95 \% \mathrm{CI}$ : $1.027-1.110, P=0.001)$. In this context, the risk for asthma in the children with vitamin D deficiency was 6.3 times of those with normal vitamin D level.

\section{Discussion}

The main point of the study was that the presence of vitamin D deficiency could effectively predict increased risk for childhood asthma; however, the severity or control status of this event could not be predicted by confirming vitamin D deficiency. Some case-controlled studies could show the association between vitamin D deficiency and asthma in children. In a study by Arikoglu et al. [15], the association between vitamin $\mathrm{D}$ deficiency and increased risk for asthmatic attack in children was indicated. In this regard, the mean serum level of vitamin $\mathrm{D}$ in the asthma attack group was significantly lower than that of the controlled asthma group. They also showed that the reduced vitamin $\mathrm{D}$ could increase the risk for asthma attack by 16 times, however we could not demonstrate relationship between vitamin D deficiency and asthma attack in our children. In another study by Hatami et al. [16] and similar to our finding, there was a significant decrease in the concentration of serum 25- hydroxy $(\mathrm{OH})$ vitamin $\mathrm{D}$ in the asthmatic patients as compared. Also, 56\% of children were vitamin $\mathrm{D}$ deficient that was lower than that revealed in our study as $73.6 \%$. In a review on observational studies including 3 prospective, 16 case-control and 14 cross-sectional studies, it was suggested a pooled positive association of vitamin D levels with better asthma control,

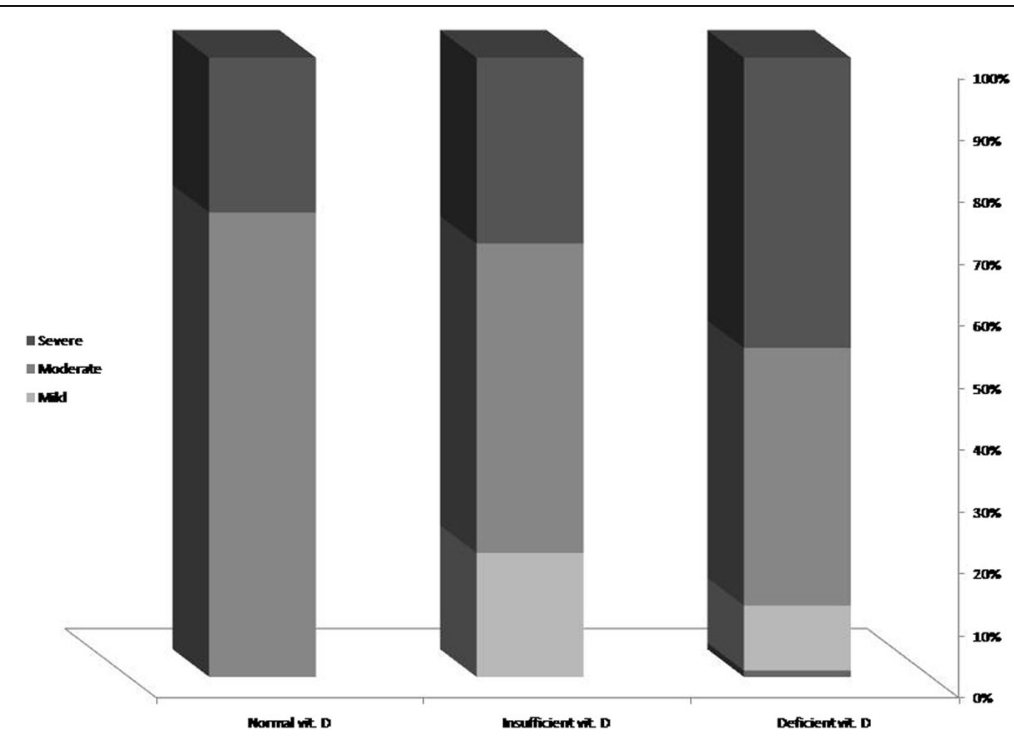

Fig. 1 The association between vitamin D deficiency and severity of asthma 


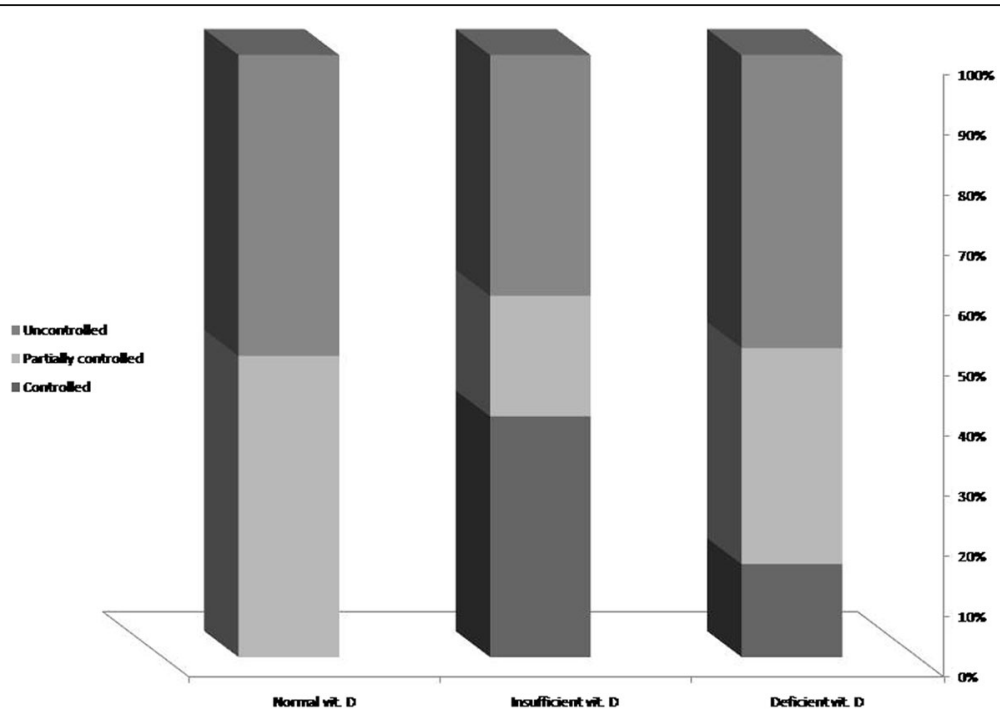

Fig. 2 The association between vitamin D deficiency and control status of asthma

reduced use of asthma medication, fewer asthma exacerbations and lower utilization of health care facilities for urgent treatment [17]. Even, some clinical trials structured as a systematic review demonstrated that the use of supplement vitamin D could be effective in reducing the risk for asthma progression. In a metaanalysis by Riverin et al. [18] in 2015 and by reviewing eight randomized controlled trial including 573 children aged 3 to 18 years; it was revealed that the use of vitamin D supplement led to a reduced risk of asthma exacerbations with the relative risk of 0.41 . In this regard, the serum 25-hydroxy vitamin D level was higher in the vitamin $\mathrm{D}$ group at the end of the intervention. In total, comparing our study with the previous reports shows two important points. First, according the reports on prevalence of vitamin $\mathrm{D}$ deficiency among our children, most Iranian children suffer vitamin D deficiency that even in our control group; about half of the children in different geographical areashave vitamin D deficiency. In a study by Saki et al. [19] in southern Iran, shocking statistics was reported from vitamin D among children so $81.3 \%$ of them were

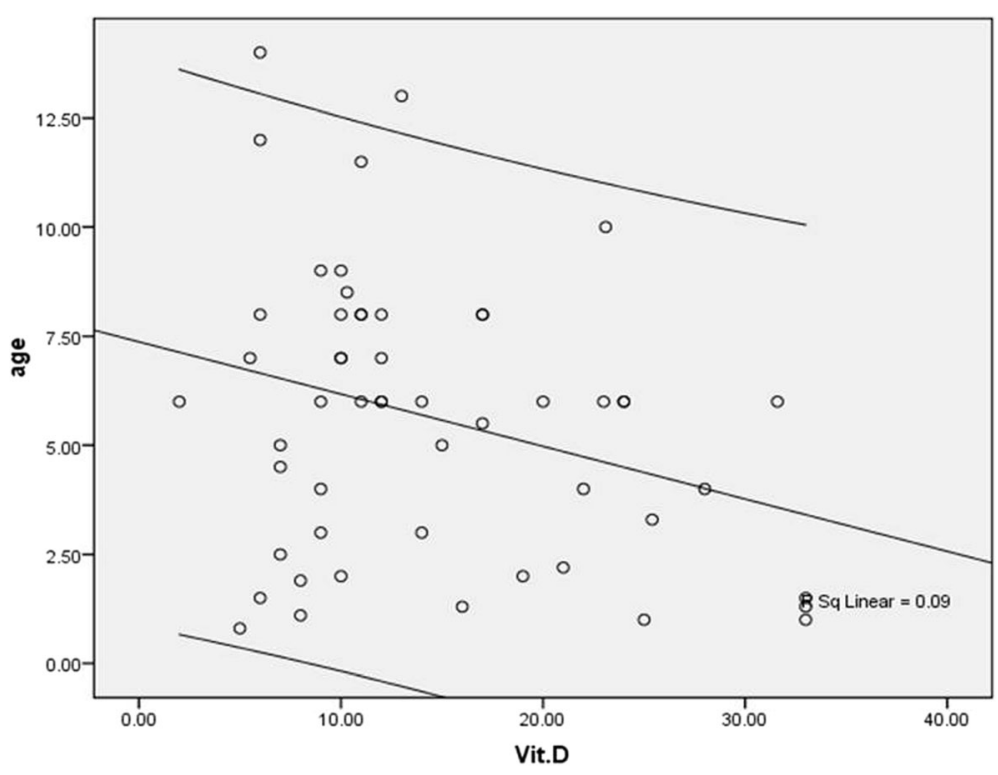

Fig. 3 Correlation between level of vitamin D and patients' age 
Table 2 Multivariate logistic regression analysis to determine association between asthma and serum level of vitamin $D$

\begin{tabular}{llllllllll}
\hline & B & S.E. & Wald & df & Sig. & Exp & \multicolumn{3}{c}{$95.0 \%$ C.l.for EXP (B) } \\
\cline { 7 - 9 } & & & & & & (B) & Lower & Upper \\
\hline Vit.D & .065 & .020 & 10.805 & 1 & .001 & 1.068 & 1.027 & 1.110 \\
sex & .240 & .418 & .330 & 1 & .566 & 1.272 & .560 & 2.887 \\
age & .000 & .061 & .000 & 1 & .987 & .999 & .887 & 1.125 \\
Constant & -1.527 & .788 & 3.754 & 1 & .053 & .217 & & \\
\hline
\end{tabular}

vitamin $\mathrm{D}$ deficient. In another survey by Kelishadi et al. [20] in Isfahan province, vitamin D deficiency and insufficiency were detected in 37.9 and $46.3 \%$ of children, respectively. Second, the reports found higher risk of vitamin D deficiency for asthmatic children when compared to general population emphasizing administration of supplement vitamin D in these children subgroup.

Some mechanisms have been introduced to explain association between vitamin D deficiency and progression of asthma especially in infants. One mechanism explained focus regulatory role of vitamin D in immune system functions. The oxidative stress plays a major role in asthma exacerbations (4). Vitamin D deficiency enhances oxidative stress (5). Vitamin D deficiency was shown to be effective on Th1 and Th2 cytokines secretion, which can contribute to the development of atopy. In fact, neonates with vitamin D deficiency develop a Th2-skewed pulmonary immune phenotype and reduced $\mathrm{IL}-10$-secreting $\mathrm{T}$ regulatory cells affecting neonatal pulmonary function [20-22]. Vitamin D Receptor (VDR) activation inhibits IgE expression in B cells and enhances IL-10 expression, which studies show can protect against atopic conditions [23-25]. Besides, it has been shown that 1,25dihydroxycholecalciferol, the active form of vitamin D, is a paracrine factor that modulates fetal lung maturation and airway smooth muscle cell proliferation and differentiation [26, 27]. In one survey D supplementation associated with asthma controllers could significantly improve $\mathrm{FEV}_{1}$ in mild to moderate persistent asthma after 24 weeks (2).

Therefore, it seems that using vitamin D3 supplementation can be effective on blocking the increase in tracheal contractility that developed in the vitamin D deficient children.

\section{Conclusion}

In summary, vitamin $\mathrm{D}$ deficiency and insufficiency is a common finding among asthmatic children that may be associated by the physiological mechanism of this phenomenon. In fact, it seems that the use of supplement vitamin $\mathrm{D}$ can prevent progression of childhood asthma. Providing vitamin $\mathrm{D}$ in children especially among Iranian people with high prevalence of vitamin D deficiency can be very helpful to prevent upward trending severe asthma among children with vitamin D deficiency. Further longitudinal studies on the effects of vitamin D supplementation in childhood asthma control would help understanding real life outcomes.

\section{Abbreviation \\ ANOVA: Analysis of variance; GINA: Global initiative for asthma; $\mathrm{OH}$ : Hydroxy; RIA: Radioimmunoassay; VDR: Vitamin D receptor; EPR3: Expert panel report 3}

\section{Acknowledgements}

The authors wish to thank Rasoul-e-Akram Hospital Clinical Research Development Center.

\section{Funding}

There was no any funding support for this project.

\section{Availability of data and material}

The datasets were generated during July 2014 and analyzed during August 2014. The data that supports the findings of this study are available from Dr. Niloofar Sedghi, but restrictions apply to the availability of these data which were used under license for the current study, and so are not publicly available. Data are however available from the authors upon reasonable request and with permission of Dr. Niloofar Sedghi.

\section{Authors' contributions}

$\mathrm{NE}, \mathrm{DB}$ drafted the primary idea of the manuscript and gathered the data. NS participated in the design of the study and performed the statistical analysis. NE conceived of the study, and participated in its design. FA, SF had a role in: referring patients; constructing and setting the questionnaire to fill out by the patients; also entering the data in SPSS software. All authors read and approved the final manuscript.

\section{Competing interests}

The authors declare that they have no competing interests.

\section{Consent for publication}

The manuscript does not contain any individual person's data in any form.

\section{Ethics approval and consent to participate}

This study was carried out in accordance with Declaration of Helsinki. This study was approved by the ethics committee of Shahid Beheshti University of Medical Sciences.

\section{Author details}

${ }^{1}$ Pediatric Nephrology Research Center, Faculty of Medicine, Mofid Children's Hospital, Shahid Beheshti University of Medical Sciences, Tehran, Iran. ${ }^{2}$ Department of Pediatrics Cardiology, Faculty of Medicine, Mofid Children's Hospital, Shahid Beheshti University of Medical Sciences, Tehran, Iran.

${ }^{3}$ Department of Emergency Medicine, Faculty of Medicine, Mofid Children's Hospital, Shahid Beheshti University of Medical Sciences, Tehran, Iran.

${ }^{4}$ Allergy and Clinical Immunology Department, Mofid Children's Hospital,

Shahid Beheshti University of Medical Sciences, Tehran, Iran.

Received: 13 April 2016 Accepted: 5 October 2016

Published online: 17 December 2016

References

1. Busse WW, Boushey HA, Camargo CA, Evans D, Foggs MB, Janson SL, et al. National asthma education guidelines for the prevention program expert panel report 3, guideline for the diagnosis and management of asthma. 2007.

2. Arshi S, Fallahpour M, Nabavi M, Bemanian MH, Javad-Mousavi SA, Nojomi M, et al. The effects of vitamin D supplementation on airway functions in mild to moderate persistent asthma. Ann Allergy Asthma Immunol. 2014;113:404-9.

3. Moffatt MF, Kabesch M, Liang L, Dixon AL, Strachan D, Heath S, et al. Genetic variants regulating ORMDL3 expression contribute to the risk of childhood asthma. Nature. 2007;448:470-3. 
4. Caffarelli C, Dascola CP, Peroni D, Ricò S, Stringari G, Varini M, et al. Airway acidification in childhood asthma exacerbations. Allergy Asthma Proc. 2014; 35(3):51-6.

5. Lan N, Luo G, Yang X, Cheng Y, Zhang Y, Wang X, et al. 25-Hydroxyvitamin D3-Deficiency Enhances Oxidative Stress and Corticosteroid Resistance in Severe Asthma Exacerbation. PLoS One. 2014;9(11):e111599. doi:10.1371/ journal.pone.0111599.

6. Nguyen TM, Guillozo H, Marin L, Tordet C, Koite S, Garabedian M. Evidence for a vitamin D paracrine system regulating maturation of developing rat lung epithelium. Am J Physiol. 1996;271(Pt 1):L392-9.

7. Edelson JD, Chan S, Jassal D, Post M, Tanswell AK. Vitamin D stimulates DNA synthesis in alveolar type-II cells. Biochim Biophys Acta. 1994;1221:159-66.

8. Gaultier C, Harf A, Balmain N, Cuisinier-Gleizes P, Mathieu H. Lung mechanics in rachitic rats. Am Rev Respir Dis. 1984;130:1108-10.

9. Nguyen TM, Guillozo H, Marin L, Dufour ME, Tordet C, Pike JW, et al. 1,25dihydroxyvitamin D3 receptors in rat lung during the perinatal period: regulation and immunohistochemical localization. Endocrinology. 1990;127: 1755-62.

10. Marin L, Dufour ME, Nguyen TM, Tordet C, Garabedian M, et al. Maturational changes induced by 1 alpha, 25-dihydroxyvitamin D3 in type II cells from fetal rat lung explants. Am J Physiol. 1993;265:L45-52.

11. Marin L, Dufour ME, Tordet C, Nguyen M. 1,25(OH)2D3 stimulates phospholipid biosynthesis and surfactant release in fetal rat lung explants. Biol Neonate. 1990;57:257-60.

12. Ebrahimi M, Khashayar P, Keshtkar A, Etemad K, Dini M, Mohammadi Z, et al. Prevalence of vitamin D deficiency among Iranian adolescents. J Pediatr Endocrinol Metab. 2014;27(7-8):595-602. doi:10.1515/jpem-2013-0428.

13. Colice GL. Categorizing asthma severity: an overview of national guidelines. Clin Med Res. 2004;2:155-63.

14. Rabe KF, Adachi M, Lai CK, Soriano JB, Vermeire PA, Weiss KB, et al. Worldwide severity and control of asthma in children and adults: the global asthma insights and reality surveys. J Allergy Clin Immunol. 2004;114:40-7.

15. Arikoglu T, Kuyucu S, Karaismailoglu E, Batmaz SB, Balci S. The association of vitamin D, cathelicidin, and vitamin D binding protein with acute asthma attacks in children. Allergy Asthma Proc. 2015;36:51-8. doi:10.2500/aap.2015.36.3848.

16. Hatami G, Ghasemi K, Motamed N, Firoozbakht S, Movahed A, Farrokhi S. Relationship between vitamin D and childhood asthma: a case-control study. Iran J Pediatr. 2014;24:710-4.

17. Kolokotroni O, Middleton N, Kouta C, Raftopoulos V, Yiallouros PK. Association of serum vitamin D with asthma and atopy in childhood: review of epidemiological observational studies. Mini Rev Med Chem. 2015;15:881-99.

18. Riverin BD, Maguire JL, Li P. Vitamin D supplementation for childhood asthma: a systematic review and meta-analysis. PLoS One. 2015;10:e0136841. doi:10.1371/journal.pone.0136841. eCollection 2015.

19. Saki F, Dabbaghmanesh MH, Omrani GR, Bakhshayeshkaram M. Vitamin D deficiency and its associated risk factors in children and adolescents in southern Iran. Public Health Nutr. 2015;1-6. http://dx.doi.org/10.1017/ S1368980015001925.

20. Staeva-Vieira TP, Freedman LP. 1,25-dihydroxyvitamin D3 inhibits IFNgamma and IL-4 levels during in vitro polarization of primary murine CD4+ T cells. J Immunol. 2002;168:1181-9.

21. McFadden JP, Thyssen JP, Basketter DA, Puangpet P, Kimber I. T helper 2 immune skewing in pregnancy/early life, chemical exposure and the development of atopic disease and allergy. Br J Dermatol. 2015;172:584-91. doi:10.1111/bjd.13497. Epub 2015 Jan 28.

22. Vasiliou JE, Lui S, Walker SA, Chohan V, Xystrakis E, Bush A, et al. Vitamin D deficiency induces Th2 skewing and eosinophilia in neonatal allergic airways disease. Allergy. 2014;69:1380-9. doi:10.1111/all.12465.

23. Milovanovic M, Heine G, Hallatschek W, Opitz B, Radbruch, et al. Vitamin D receptor binds to the epsilon germline gene promoter and exhibits transrepressive activity. J Allergy Clin Immunol. 2010;126:1016-23. doi:10. 1016/j.jaci.2010.08.020. PubMed: 20926124

24. Heine $G$, Niesner $U$, Chang H-D, Steinmeyer A, Zügel U, Zuberbier T, et al. 1, 25-dihydroxyvitamin $D(3)$ promotes $\mathrm{IL}-10$ production in human $\mathrm{B}$ cells. Eur J Immunol. 2008;38:2210-8. doi:10.1002/eji.200838216. PubMed: 18651709 .

25. Hartmann B, Heine G, Babina M, Steinmeyer A, Zugel U, Radbruch A, et al. Targeting the vitamin $D$ receptor inhibits the $B$ cell-dependent allergic immune response. Allergy. 2011;66:540-8. doi:10.1111/j.1398-9995.2010. 02513.x. PubMed: 21121929.
26. Nguyen M, Trubert CL, Rizk-Rabin M, Rehan VK, Besançon F, Cayre YE, et al. 1,25-Dihydroxyvitamin D3 and fetal lung maturation: immunogold detection of VDR expression in pneumocytes type II cells and effect on fructose 1,6 bisphosphatase. J Steroid Biochem Mol Biol. 2004;89-90:93-7. doi:10.1016/j.jsbmb.2004.03.054.

27. Yurt M, Liu J, Sakurai R, Gong M, Husain SM, Siddiqui MA, et al. Vitamin D supplementation blocks pulmonary structural and functional changes in a Rat model of perinatal vitamin D deficiency. Am J Physiol Lung Cell Mol Physiol. 2014;307:L859-67. doi:10.1152/ajplung.00032.2014.

\section{Submit your next manuscript to BioMed Central and we will help you at every step:}

- We accept pre-submission inquiries

- Our selector tool helps you to find the most relevant journal

- We provide round the clock customer support

- Convenient online submission

- Thorough peer review

- Inclusion in PubMed and all major indexing services

- Maximum visibility for your research

Submit your manuscript at www.biomedcentral.com/submit
Biomed Central 